\title{
Augmented Realitybook Pengenalan Tataletak Bangunan Pura Luhur Uluwatu Beserta Landscape Alam
}

\author{
Kadek Agus Jayadi Putra ${ }^{1}$, Padma Nyoman Chrisnapati ${ }^{2}$, Made Windu Antara Kesiman ${ }^{3}$, I Gede Mahendra \\ Darmawiguna $^{4}$ \\ Jurusan Pendidikan Teknik Informatika \\ Universitas Pendidikan Ganesha \\ Singaraja, Bali \\ E-maill:agusjayadiputra@yahoo.com ${ }^{1}$,crisnapati@yahoo.com²,dekndu@yahoo.com ${ }^{3}$,igd.mahendra@gmail.com
}

\begin{abstract}
Abstrak-Pura Luhur Uluwatu merupakan salah satu Sad Kahyangan di Bali yang berfungsi sebagai tempat pemujaan Dewa Rudra. Pura Luhur Uluwatu terletak disebelah barat Desa Pecatu termasuk wilayah Kecamatan Kuta Selatan, Daerah Tingkat II Badung. Pura ini di atas tebing yang sangat terjal dengan ketinggian 97 meter dari permukaan laut. Selain sebagai tempat pemujaan oleh umat Hindu, pura ini juga dijadikan sebagai tujuan wisata baik oleh wisatawan domestic maupun wisatawan mancanegara karena memiliki pesona alam yang sangat indah. Pura Luhur Uluwatu merupakan warisan kebudayaan yang patut dilestarikan. Salah satu upaya pelestariannya adalah dengan menggabungkan kebudayaan dengan teknologi Augmented Reality.
\end{abstract}

Penelitian ini bertujuan untuk membangun sebuah aplikasi Augmented Reality Book Pengenalan Tata Letak Bangunan Pura Luhur Uluwatu beserta Landscape Alam. Pengembangan aplikasi berbasis Android ini menggunakan beberapa software yakni Blender, Unity 3D dan library vuforia untuk menampilkan objek 3 dimensi bangunan ke dalam sebuah lingkungan nyata. Metode yang digunakan dalam penelitian ini adalah metode waterfall. Hasil akhir dari penelitian ini berupa buku yang berisikan gambar beserta informasi terkait dengan Pura Luhur Uluwatu, gambar dari buku ini berfungsi sebagai marker untuk menampilkan objek bangunan Pura Luhur Uluwatu beserta Landscape Alam lengkap dengan suara narasi.

Kata kunci: Pura Luhur Uluwatu, aplikasi, Augmented Reality Book, Android, Blender, Unity3D, library Vuforia.

Abstract - Pura Luhur Uluwatu is one of "purasad kahyangan" which serves as a place to worship of Lord Rudra. Pura Luhur Uluwatu is located in the west part of the Pecatu village, including South Kuta subdistrict, Badung regency. This temple is on topofaverysteepcliff with a height of 97 meters above seal evel. Apart for praying, the temple is also used as a tourist destination by both domestic and foreign tourists because of its beautiful natural view. Pura Luhur Uluwatu is also a cultural heritage that should be preserved. One of the conservation effortsis to combine culture with Augmented Reality technology. This study aims to buildan app Augmented Reality Book Introduction to Uluwatu Building Layout within Its Natural Landscape. This Android-based application development applied some software involving Blender, Unity $3 D$, and vuforia library for building $3 D$ display objects into areal environment. The method use din this study was the waterfall method. The end result of this research was a book containing images and related informationtothe Pura Luhur Uluwatu in which the pictures of the book servedasa marker to display building objects and Uluwatu Natural Landscape completed with narration.

Key Words: Pura Luhur Uluwatu, application, Augmented Reality Book, Android, Blender,Unity3D, library Vuforia.

\section{I.PENDAHULUAN}

Indonesia adalah sebuah Negara kepulauan yang terdiri dari banyak pulau. Pulau-pulau di Indonesia memiliki keunikan tersendiri sehingga dapat menarik minat warga local maupun asing untuk menikmatinya. Hal ini yang dimanfaatkan oleh pemerintah Indonesia agar dapat meningkatkan pendapatan Negara Indonesia. Pemerintah Indonesia melakukan berbagai tindakan agar dapat mengembangkan sector pariwisata. Pariwisata merupakan suatu perjalanan yang dilakukan untuk rekreasi atau liburan dalam jangka waktu yang pendek dengan tujuan memperoleh kenikmatan, mencari kepuasan, memperoleh sesuatu hal yang baru, beristirahat dari kesibukan, memperbaiki kesehatan, dan lain sebagainya[6].

Dalam menciptakan hubungan yang harmonis antara manusia dengan Tuhan, manusia wajib berterima kasih, berbhakti, dan selalu sujud 
kepada Tuhan Yang Maha Esa. Rasa terima kasih dan sujud bhakti itu dapat dinyatakan dalam bentuk puja dan puji terhadap kebesaranNya, yaitu: dengan beribadah dan melaksanakan perintahnya, dengan melaksanakan Tirtha Yatra atau Dharma Yatra, yaitu kunjungan ke tempat-tempat suci, dengan mempelajari, menghayati dan mengamalkan ajaranajaran agama. Tempat suci bagi umat Hindu disebut dengan pura. Salah satu pura yang ada di Bali adalah Pura Luhur Uluwatu sebagai stana Dewa Rudra. Pura ini merupakan salah satu tempat suci yang sering dikunjungi oleh umat Hindu. Pura Luhur Uluwatu ini berada di Desa Pecatu Kecamatan Kuta Kabupaten Badung. Pura Luhur Uluwatu terancam mengalami kerusakan bahkan akan menghilang suatu hari nanti karena beberapa hal yakni, pada tahun 2002 lalu, salah satu meru tumpang tiga tempat (linggih) Ida Betara Luhur Uluwatu tersambar petir. Dari peristiwa tersebut, satu sendi dari Sembilan sendi yang ada hancur berkepingkeping. Peristiwa ini diyakini sebagai pertanda buruk dari alam[5]. Satu lagi yang perlu dipertimbangkan tentang keberadaan Pura Luhur Uluwatu adalah frekuensi gempa yang cukup tinggi karena Bali khususnya dan Indonesia umumnya dilintasi oleh Pasificringoffire yang merupakan daerah yang sering mengalami gempa bumi dan letusan-letusan gunung berapi yang mengelilingi cekungan Samudra Pasifik[5]. Oleh karena itu tebing yang semula kokoh lama-lama bias lemah dan rapuh karena gempa. Oleh sebab itu perlu diupayakan pengembangan wisata alam yang mampu memberikan gambaran tentang keadaan tempat tersebut. Salah satu hal yang dapat diupayakan adalah dengan menggabungkan kebudayaan dengan teknologi.

Salah satu teknologi yang dapat dimanfaatkan dalam hal ini adalah Augmented Reality. Teknologi ini menggabungkan benda maya dua dimensi ataupun tiga dimensi ke dalam lingkungan nyata tiga dimensi dan kemudian memproyeksikan benda-benda maya tersebut dalam waktu nyata. Keuntungan dari teknologi ini dapat menarik masyarakat untuk mempelajari kebudayaan yang ditampilkan secara interaktif dari pada hanya membaca buku yang berisikan teks dan beberapa gambar. Beberapa penerapan teknologi Augmented Reality di bidang kebudayaan yang sudah berhasil dibuat adalah "Pengembangan Aplikasi Augmented Reality Book Pengenalan Tata Letak Bangunan Pura Ulun Danu Batur" karya I Made Yudiantara. Kesimpulan dari penelitian tersebut adalah "Penggunaan aplikasi Augmented Reality Book pengenalan Pura Ulun Danu Batur, dapat digunakan sebagai sarana guna menarik minat pembaca untuk mempelajari, memperkenalkan dan melestarikanPura Batur"(Yudiantara,2014:26).

\section{II.KAJIANTEORI}

\section{A.Augmented Reality}

Augmented Reality (AR) adalah sebuah teknologi yang pada awal dikembangkannya memiliki lingkup utama di "visual augmentation", penambahan objek digital dalam. Secara sederhana Augmented Reality bias didefinisikan sebagai lingkungan nyata yang ditambahkan obyek virtual. Penggabungan obyek nyata dan virtual ini dimungkinkan dengan teknologi display yang sesuai serta interaktivitas dimungkinkan melalui perangkat-perangkat input tertentu.

Ronald T.Azuma (1997) mendifinisikan Augmented Reality sebagai system yang menggabungkan dunia nyata dan virtual, interaktif dalam real-time dan register dalam 3D. Sistem Augmented Reality juga memiliki tiga komponen utama yaitu:

1. Tracking system menentukan posisi dan orientasi obyek- obyek dalam dunia nyata.

2. Graphic system menggunakan informasi yang disediakan tracking system untuk menggambarkan gambar-gambar virtual pada tempat yang sesuai, sebagai contoh melalui obyek-obyek nyata.

3. Tampilan system menggabungkan dunia nyata dengan gambar virtual dan mengirimkan hasilnya kepengguna

(Rakacita,2011).[5]

\section{B.Vuforia}

Vuforia merupakan software library untuk Augmented Reality, yang menggunakan sumber yang konsisten mengenai computer vision yang focus pada image recognition. Vuforia

Mempunyai banyak fitur-fitur dan kemampuan, yang dapat membantu pengembang untuk mewujudkan pemikiran mereka tanpa adanya batas secara teknikal. Dengan support untuk iOS, Android, dan Unity3D, platform Vuforia mendukung para pengembang untuk membuat aplikasi yang dapat digunakan dihampir seluruh jenis smartphone dan tablet.

\section{C.Augmented Reality Book}

Augmented Reality Book (AR-Book) atau yang dalam bahasa Indonesia berarti buku berbasis Augmented Reality merupakan penggabungan antara buku biasa dengan teknologi Augmented Reality. 


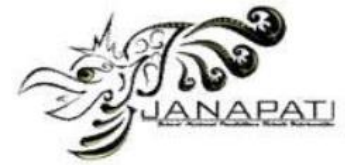

AR-Book secara garis besar memiliki dua komponen utama, yaitu buku yang dilengkapi dengan marker berjenis Quick Response Code $(Q R C)$ pada hampir setiap halamannya, dan yang kedua yaitu peralatan untuk menangkap marker dan menampilkan hasilnya. Alat tersebut dapat berbentuk handheld display (HHD), headmounted display (HMD), virtual retinal display (VRD), atau bahkan tampilan berbasis layar biasa.

Augmented Reality Book termasuk dalam kategori sumber belajar yang didesain khusus, karena dikembangkan sebagai komponen dalam hal mempermudah pengguna memahami isi buku dengan cara menampilkan objek berupa dimensi yang tertera pada buku. Augmented Reality Book juga dapat dikatakan sebagai media karena berbentuk bahan cetakan yang dapat menampilkan informasi yang diperlukan.

\section{D.Pura Luhur Uluwatu}

Dalam konsep kosmologi pura Hindu di Bali, Pura Luhur Uluwatu termasuk salah satu Sad Kahyangan. Pura Sad Kahyangan terdiri atas enam buah pura, yang dianggap menempati kedudukan tertinggi dan menjadi pemujaan seluruh pemeluk Hindu di Bali. Pura-pura itu adalah Pura Besakih sebagai yang terbesar, Pura Lempuyang, Pura Batu karu (Batukau), Pura Sakenan, Pura Uluwatu, dan Pura Andakasa. Dalam satu sumber yang lain, disebutkan bahwa Pura Sad Kahyangan terdiri atas: Besakih, Bukit Lamongan, dan Uluwatu. Batukaru, Yeh Jeruk, dan Gua Lawah. Monografi Daerah Bali yang merupakan terbitan resmi Pemerintah Daerah Bali, menyebutkan bahwa Pura Sad Kahyangan didirikan untuk melayani pemujaan penduduk pedesaan, padamasa-masadesa Bali asli.

Kedatangan Dang Hyang Nirartha ke Bali, berlangsung sejalan dengan merosotnya Agama dan kebudayaan Hindu di seluruh Jawa. Proses islamisasi yang sedang melanda kepulauan Nusantara dalam abad XV-XVI, telah mempercepat proses keruntuhan Agama dan budaya Hindu di Jawa. Beliau memilih Bali sebagai lokasi pusat pertahanan, karena Bali belum terjamah oleh dampak Islamisasi. Peranan Raja Dalem Watu Renggong sebagai penguasa Bali yang terkenal bijaksana dan budayawan, sangat kuat pengaruhnya dalam membina kepercayaan masyarakat terhadap agama dan budaya Hindu. Ketiga, kegagalan utusan Sunan Prapen yang dikirim untuk mengislamkan Raja Dalem Watu Renggong. Dalam tahun 1464M, Dang Hyang Nirartha meninggalkan puing kraton Majapahit menuju Daha. Di Daha Nirartha kawin dengan putri Dang Hyang Panawaran bernama Diah Komala.
ISSN 2087-2658
Dari perkawinan ini lahir dua orang putra,satu perempuan bernama Dayu Swabawa dan satu lakilaki bernama Ida Wiraga Sandi. Kemudian Dang Hyang Nirartha melanjutkan perjalanannya ke Pasuruan. Di Pasuruan Nirartha kawin dengan putri Dang Hyang Panawasikan bernama Diah Sanggawati. Dari perkawinan ini lahir empat orang anak laki-laki, antara lain Ida Kulwan, Ida Wetan, Ida Ler, dan Ida Lor. Dang Hyang Nirartha melanjutkan perjalanannya menuju Blambangan. Beliau hanya disertai oleh ke enam putra purtinya. Di Blambangan Dang Hyang Nirartha kawin dengan adik Sri Aji Juru raja Kerajaan Blambangan, bernama Sri Patni Keniten. Dari perkawinan ini, lahir tiga orang putra, seorang putrid bernama Dayu Rai, dan dua orang laki-laki bernama Ida Wetan dan Ida Keniten.

Di Purancak Dang Hyang Nirartha mulai menyebarluaskan ajaran Hindu (Siwa) kepada masyarakat. Awal penyebaran ini kemudian diabadikan dengan mendirikan sebuah pura pemujaan, yangdinamai Pura Purancak. Perkembangan kemudian telah mengubah fungsi pura ini, tidak saja sebagai pemujaan terhadap Siwa Sidanta, tetapi juga sebagai pemujaan terhadap Nirartha yang telah diperdewakan sebagai Betara Sakti Wawu Rauh.

Pengembaraan Dang Hyang Nirartha dan Keluarga dilanjutkan menuju ke timur. Dalam sumber-sumber tradisi disebutkan desa-desa yang dikunjungi antara lain Gading Wani, Mundeh, Kapal, Kuta, dan kemudian menuju desa Mas. Di Desa Gading Wani, Nirartha telah berhasil menyembuhkan penduduk yang sedang dilanda epidemi. Ternyata selain sebagai pendeta, maka Nirartha adalah juga seorang yang sakti dalam pedukunan.

Di desa Mas Dang Hyang Nirartha dan keluarga diterima oleh Ki Bendesa Mas. Dari desa ini Nirartha mulai menyebarkan ajaran Siwa Sidanta. Ki Bendesa dan rakyatnya, menjadi murid-murid Nirartha yang pertama. Kedatangan Dang Hyang Nirartha di desa Mas, beritanya sampai kekraton Gelgel.

Sebagai seorang raja besar, yang senantiasa haus dengan ilmu keagamaan, budaya, dan kesakten, Dalem Watu Renggong ingin sekali berguru dengan pendeta sakti itu.

Dang Hyang Nirartha mendapat kesempatan untuk memperbaharui dan mempertebal kepercayaan dan sikap religius rakyat Bali. Perbuatan ini sejalan dengan kebijakan raja Dalem Watu Renggong untuk menangkal timbulnya krisis kepercayaan dan penyebaran agama Islam ke Bali.

Dang Hyang Nirartha meminta kepada 


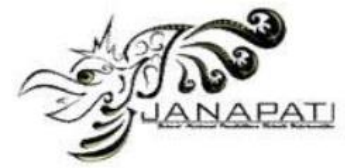

ISSN 2087-2658

Jurnal Nasional Pendidikan Teknik Informatika (JANAPATI)

Volume 4, Nomor 2, Juli 2015

Dalem Watu Renggong agar diperkenankan melaksanakan dharma yatra ke seluruh Bali dan daerah-daerah yang berada di bawah kekuasaannya. Tujuan perjalanan suci ini untuk menyebarkan dan memperkuat sendi-sendi agama dan kebudayaan Hindu (Siwa) kepada seluruh masyarakat Bali. Dalam perjalanan suci inilah peranan Dang Hyang Nirartha sangat menonjol dalam pembangunan dan pembinaan Pura Uluwatu.

Dalam Dharma Yatraini. Dang Hyang Nirartha melaksanakan upacara pemujaan di Pura Uluwatu untuk memperoleh tirta palukatan untuk menyucikan pulau Bali. Keberhasilan Nirartha memperoleh tirta palukatan di Pura Uluwatu ini, tampaknya telah memberikan arah kepadanya untuk kemudian menetapkan pura ini sebagai tempat yang paling tepat untuk moksa.

Dalam sumber tradisional dinyatakan bahwa Nirartha telah mengakhiri dharmanya dan moksa di Pura Uluwatu. Sejak itu, Pura Uluwatu selain dipuja sebagai Sad Kahyangan juga dijadikan sebagai petilasan pemujaan bagi Dang Hyang Nirartha sebagai Betara Sakti Wawu Rauh. Peranan Pura Luhur Uluwatu muncul dalam system kepuraan di Bali, setelah Nirartha memasukkan pura itu ke dalam konsep Dharma Yatra dan sebagai land mark bahwa Bali tetap pemeluk Hindu yang taat. [1]

\section{III.METODOLOGI}

\section{A.Analisis Masalah dan Usulan Solusi}

Pengembangan Aplikasi Augmented Reality (AR) Book Pengenalan Tata Letak Bangunan Pura Luhur Uluwatu dan Landscape Alam ini mengunakan proses SDLC (System Development Life Cycle) dengan model waterfall yaitu model yang bersifat sistematis dan berurutan dalam membangun perangkat lunak, mulai dari tahap analisis, desain, implementasi, testing, operation, dan maintenance.

Tahap pertama yang dilakukan adalah mencari dan mengumpulkan kebutuhan secara lengkap kemudian dianalisis dan didefinisikan yang merupakan bagian dari requirements analysis and definition (analisis kebutuhan dan definisi) pada model tersebut. Pada tahap ini, penulis melakukan pencarian informasi dan menganalisis kenyataan mengenai Pura Uluwatu. Berdasarkan hasil analisis penulis bahwa Pura Luhur Uluwatu merupakan salah satu Sad Kahyangan di Bali yang berfungsi sebagai tempat pemujaan Dewa Rudra. Selain sebagai tempat pemujaan oleh umat Hindu, pura ini juga dijadikan sebagai tujuan wisata baik oleh wisatawan domestic maupun wisatawan mancanegara karena memiliki pesona alam yang sangat indah.
Namun tidak semua orang dapat menikmati keindahan tempat wisata ini karena keterbatasan ruang dan waktu. Selain itu Pura Luhur Uluwatu terancam mengalami kerusakan bahkan akan menghilang suatu hari nanti karena beberapa hal yakni, pada tahun 2002 lalu, salah satu meru tumpang tiga tempat (linggih) Ida Betara Luhur Uluwatu tersambar petir. Dari peristiwa tersebut, satu sendi dari Sembilan sendi yang ada hancur berkepingkeping. Peristiwa ini diyakini sebagai pertanda buruk dari alam[5]. Pura Luhur Uluwatu saat ini tepat berdiri di atas tebing terjal dan berhadapan langsung ke laut lepas sehingga akan berpotensi mengalami abrasi, jika tebing ini terus tergerus oleh ombak yang kian lama makin ganas maka bukan hal yang tidak mungkin jika suatu hari nanti pura ini akan rusak bahkan jatuh ke laut lepas karena tebing yang selama ini menjadi pondasi dari Pura Luhur Uluwatu sudah mengalami abrasi pada tingkat yang mengkhawatirkan. Satu lagi yang perlu dipertimbangkan tentang keberadaan Pura Luhur Uluwatu adalah frekuensi gempa yang cukup tinggi karena Balik hususnya dan Indonesia umumnya dilintasi oleh Pasific ring of fire yang merupakan daerah yang sering mengalami gempa bumi dan letusan-letusan gunung berapi yang mengelilingi cekungan Samudra Pasifik[3]. Oleh karena itu tebing yang semula kokoh lama-lama bias lemah dan rapuh karena gempa.

Oleh sebab itu perlu diupayakan pengembangan wisata alam yang mampu memberikan gambaran tentang keadaan tempat tersebut. Salah satu solusi yang dapat diupayakan dalam permasalahan di atas adalah dengan menggabungkan kebudayaan dengan teknologi Augmented Reality. Aplikasi dengan teknologi Augmented Reality ini akan menampilkan replica Pura Luhur Uluwatu dalam bentuk tiga dimensi (3D) disertai narasi penjelasan. Aplikasi ini akan memudahkan masyarakatd alam mempelajari bangunan, tata letak bangunan yang ada di Pura Luhur Uluwatu beserta Landscape alam tanpa harus berada langsung di area pura, serta dapat melihat bentuk bangunan 3 dimensi pura dari berbagai sisi yang diinginkan. Selain pengembangan aplikasi, juga dibuat referensi berupa buku Augmented Reality yang berisikan gambar dan informasi terkait Pura Luhur Uluwatu. Diharapkan dengan dikembangkannya aplikasi ini, dapat membantu pemerintah dalam melestarikan warisan kebudayaan yang kita miliki.

\section{B.Analisis Perangkat Lunak}

1. Kebutuhan Perangkat Lunak 
Berdasarkan analisis terhadap Aplikasi Augmented Reality Book Pengenalan Tata Letak Bangunan Pura Luhur Uluwatu beserta Landscape Alam ini, terdapat proses-proses yang akan diimplementasikan, yaitu:

a. Sistem dapat menampilkan bangunan Pura Luhur Uluwatu dalam bentuk 3D.

b. Sistem dapat menampilkan tata letak bangunan Pura Luhur Uluwatu beserta Landscape Alam lengkap dengan narasi penjelasan dalam bahasa Inggris.

c. Sistem dapat menampilkan bangunan 3D Pura Luhur Uluwatu yang dapat digerakkan ke arah kiri dan kanan serta dapat direset sesuai keinginan user.

d. Sistem dapat melakukan penelusuran bangunan 3D beserta Landscape Alam Pura Luhur Uluwatu.

Secara umum perangkat lunak ini menggunakan teknologi Augmented Reality berbasis android dengan menggunakan buku sebagai media pendukung penggunaan aplikasi. Buku dengan teknologi Augmented Reality ini secara garis besar berisikan gambar dari bangunan pura yang difungsikan sebagai penanda (marker) dan disertai penjelasan mengenai bangunan Pura Luhur Uluwatu tersebut.

2. Tujuan Pengembangan Perangkat Lunak

Aplikasi Augmented Reality Book Pengenalan Tata Letak Bangunan Pura Luhur Uluwatu beserta Landscape Alam merupakan perangkat lunak yang digunakan untuk menampilkan objek 3D berupa bangunan pura, tata letaknya beserta Landscape alamnya, tepat di atas gambar penanda ketika diarahkan oleh kamera smartphone. Aplikasi ini diharapkan mampu memenuhi proses-proses sebagai berikut:

a. Mampu menampilkan bangunan Pura Luhur Uluwatu dalam bentuk 3D.

b. Mampu menampilkan tata letak bangunan Luhur Uluwatu beserta Landscape Alam yang muncul lengkap dengan narasi penjelasan dalam bahasa Inggris.

c. Mampu menampilkan bangunan 3D Pura Luhur Uluwatu yang dapat digerakkan ke arah kiri dan kanan serta dapat direset sesuai keinginan user.

d. Mampu melakukan penelusuran bangunan 3D beserta Landscape Pura Luhur Uluwatu.

3. Masukan dan Keluaran Perangkat Lunak

a. Masukan Perangkat Lunak

Masukan dalam perangkat lunak Augmented Reality Book Pengenalan Tata Letak Bangunan Pura Luhur Uluwatu beserta Landscape Alam adalah marker atau penanda yang ditampilkan pada buku berupa gambar hasil tangkapan kamera ketika mencari marker.

b. Keluaran Perangkat Lunak

Keluaran dari perangkat lunak ini adalah objek 3D bangunan pura, tata letaknya beserta Landscape alam yang dihasilkan dari hasil pencocokan marker dan juga disertai dengan keluaran narasi penjelasan dalam bahasa Inggris serta objek 3D dapat melakukan pergerakan rotasi menggunakan softbutton.

4. Model Fungsional Perangkat Lunak

Berdasarkan analisis system yang telah dilakukan maka, digunakanlah flowchart untuk mendeskripsikan alur proses aplikasi. Flowchart

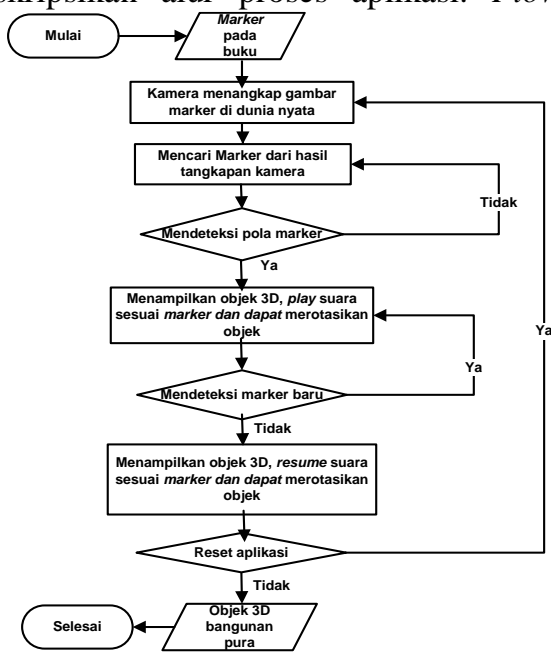

untuk Aplikasi Augmented Reality Book Pengenalan Tata Letak Bangunan Pura Luhur Uluwatu beserta Landscape Alam terlihat pada Gambar1.

Gambar1. Flowchart Rancangan Aplikasi Augmented Reality Book Pengenalan Tata Letak Bangunan Pura Luhur Uluwatu beserta Landscape Alam. 
ISSN 2087-2658

Jurnal Nasional Pendidikan Teknik Informatika (JANAPATI)

Volume 4, Nomor 2, Juli 2015

C. Perancangan Perangkat Lunak

1) Batasan Perancangan Perangkat Lunak

Adapun batasan perancangan perangkat lunak Aplikasi Augmented Reality Book Pengenalan Tata Letak Bangunan Pura Luhur Uluwatu beserta Landscape Alam dapat dipaparkan sebagai berikut.

1. Objek 3 dimensi bangunan Pura Luhur Uluwatu yang ditampilkan adalah objek 3D bangunan disesuaikan dengan kondisi fisik asli pura sebatas pada tahun 2014 .

2. Aplikasi ini hanya dapat berjalan pada perangkat android versi 4.0 (Ice Cream Sandwich) ke atas, dengan Open GLES di atas 2.0, dan arsitektur ARMv7.

2) Perancangan Arsitektur Perangkat Lunak

Perancangan arsitektur perangkat lunak menggambarkan bagian- bagian modul, struktur ketergantungan antar modul, dan hubungan antar modul dari perangkat lunak yang dibangun. Perancangan arsitektur perangkat lunak Aplikasi Augmented Reality Book Pengenalan Tata Letak Bangunan Pura Luhur Uluwatu beserta Landscape Alam digambarkan pada structure chart pada Gambar 2.

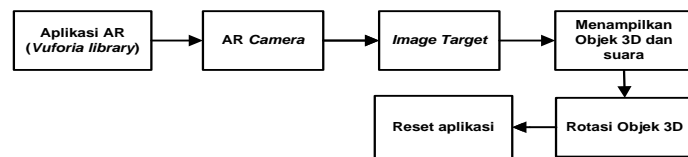

Gambar 2 Structure Chart Perangkat Lunak Aplikasi Augmented Reality Book Pengenalan Tata Letak Bangunan Pura Luhur Uluwatu beserta Landscape Alam

Usecase diagram menggambarkan fungsionalitas yang diharapkan dari sebuah sistem. Sebuah usecase merepresentasikan sebuah interaksi antara actor dengan sistem. Seorang/sebuah actor adalah sebuah entitas manusia atau mesin yang berinteraksi dengan system untuk melakukan pekerjaan-pekerjaan tertentu.Usecase diagram tersebut dapat dilihat pada Gambar 3.

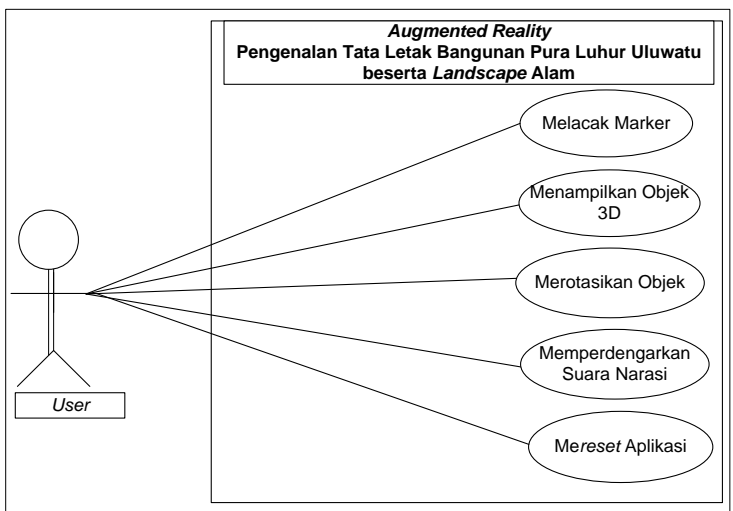

Gambar 3. UseCase Diagram Perangkat Lunak Aplikasi Augmented Reality Book Pengenalan Tata Letak Bangunan Pura Luhur Uluwatu beserta Landscape Alam

Berdasarkan UseCase Diagram tersebut, maka dapat ditentukan activity diagram dari Aplikasi Augmented Reality Book Pengenalan Tata Letak Bangunan Pura Luhur Uluwatu beserta Landscape Alam seperti terlihat pada Gambar 4.

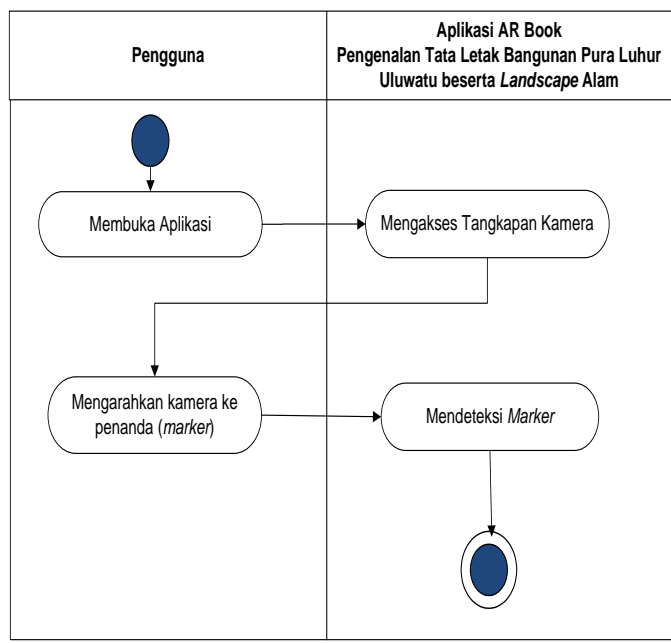

Gambar 4a. Activity Diagram Melacak Marker 
ISSN 2087-2658

Jurnal Nasional Pendidikan Teknik Informatika (JANAPATI)

Volume 4, Nomor 2, Juli 2015

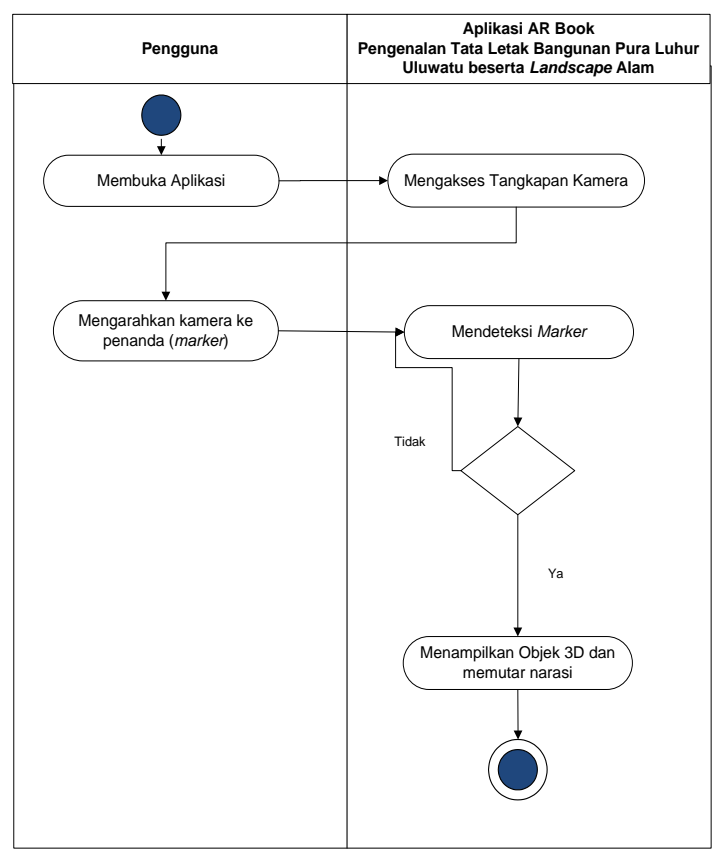

Gambar4b. Activity Diagram Menampilkan Objek $3 \mathrm{D}$

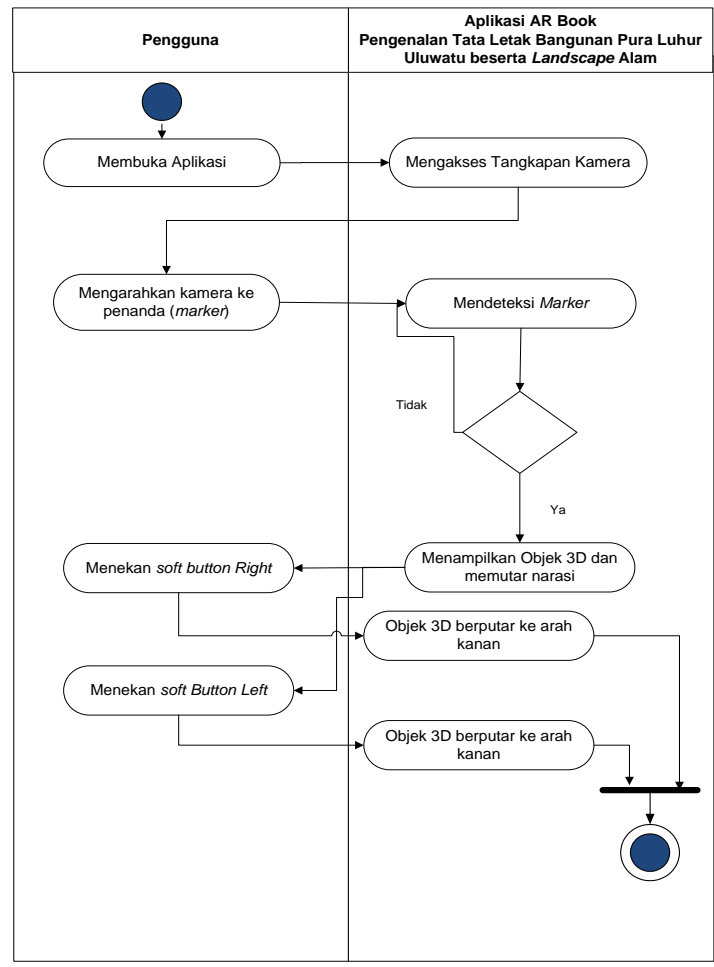

Gambar4c. Activity Diagram Merotasikan Objek 3D

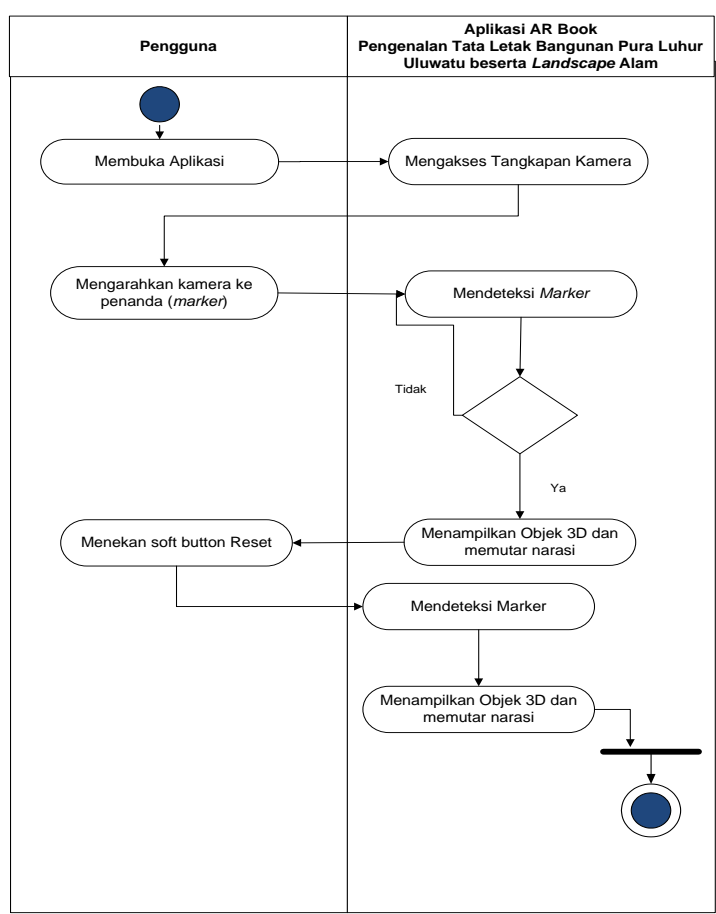

Gambar4d. Activity Diagram Mereset Aplikasi

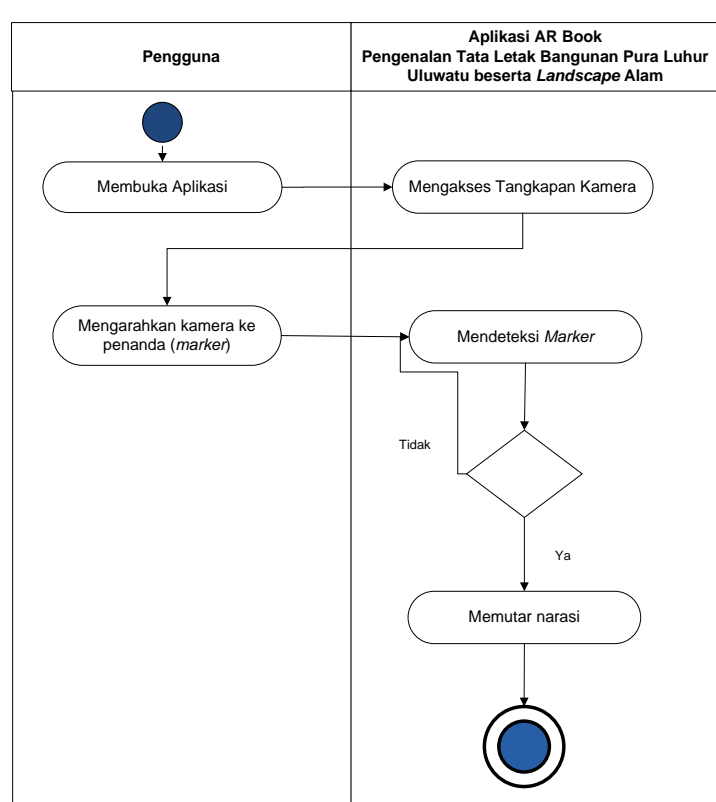

Gambar4e. Activity diagram Memutar Narasi

\section{PEMBAHASAN}

A. Implementasi Perangkat Lunak

Tahap Implementasi perangkat lunak Augmented Reality Book Pengenalan Tata Letak Bangunan Pura Luhur Uluwatu beserta Landscape Alam ini terdiri dari lingkungan implementasi perangkat lunak, batasan 
ISSN 2087-2658

Jurnal Nasional Pendidikan Teknik Informatika (JANAPATI)

Volume 4, Nomor 2, Juli 2015

implementasi perangkat lunak, implementasi arsitektur perangkat lunak, implementasi struktur data perangkat lunak serta implementasi layar antarmuka perangkat lunak.

1. Lingkungan Implementasi Perangkat Lunak Lingkungan implementasi perangkat lunak aplikasi Augmented Reality Book Pengenalan Tata Letak Bangunan Pura Luhur Uluwatu beserta Landscape Alam menggunakan beberapa perangkat lunak sebagai berikut:

a. Sistem Operasi Microsoft Windows 7 Ultimate.

b. Sistem Operasi Android 4.2.2 (JellyBean)

c. Blender 2.70a

d. Vuforia Qualcomm Augmented Reality.

e. Unity 4.2.0f4

f. SDK Android Tools.

g. Adobe Audition CS6

h. Adobe Photoshop CS6

Dan perangkat keras sebagai berikut.

a. Laptop Toshiba Satellite A665-S6070

b. Intel@ Core ${ }^{\mathrm{TM}}$ i7-720Q MCPU @ 1.60GHz.

c. VGANVIDIAGEFORCEGT310M 512MB

d. RAM 4.00GB.

e. Harddisk 500GB.

f. Dilengkapi alat input dan output.

g. Tablet Lenovo Idea tab A3000-H.

h. Resolusi 600x1024 pixels,7,0inches.

i. Quad-core1,2GHz Processor.

j. RAM1 GB.

k. Camera primer $5 \mathrm{MP}$.

2. Batasan Implementasi Perangkat Lunak

Batasan yang terdapat dalam implementasi perangkat lunak Aplikasi Augmented Reality Book Pengenalan Tata Letak Bangunan Pura Luhur Uluwatu beserta Landscape Alam yaitu sebagai berikut.

1.Objek 3 dimensi bangunan Pura Luhur Uluwatu yang ditampilkan adalah objek 3D bangunan disesuaikan dengan kondisi fisik asli pura pada tahun 2014 .

2.Aplikasi ini hanya dapat berjalan pada perangkat android Processor ARM-v7, GPU kelas mid-end, RAM 1GB, OS Android versi 4.0 (Ice Cream Sandwich) dan Ukuran layar 7 inches.

3. Implementasi Arsitektur Perangkat Lunak

Sesuai dengan hasil perancangan arsitektur perangkat lunak, dapat diimplementasikan proses yang digunakan untuk membuat perangkat lunak Augmented Reality Book Pengenalan Tata Letak Bangunan Pura Luhur Uluwatu beserta Landscape Alam, yakni QCAR Behaviour.cs, DataSet Load Behaviour.cs, Back Catcher.cs, Image Target Behaviour.cs, Default Track able Event Handler.cs, left.cs, right.cs, reset.cs, Penerapan pada perangkat lunak Unity menggunakan class-class yang disimpan dalam format file".cs".

4.

mplementasi LayarAntarmuka Perangkat Lunak

Implementasi antarmuka dilakukan sesuai dengan rancangan antarmuka yang telah dibuat sebelumnya.

a. Implementasi Antarmuka Menu Utama

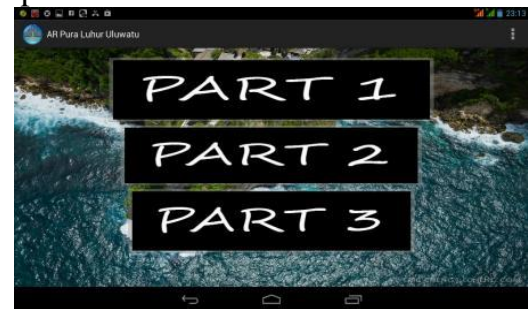

Gambar5 Implementasi Antarmuka Menu Utama

b. Implementasi Antarmuka Splash Image

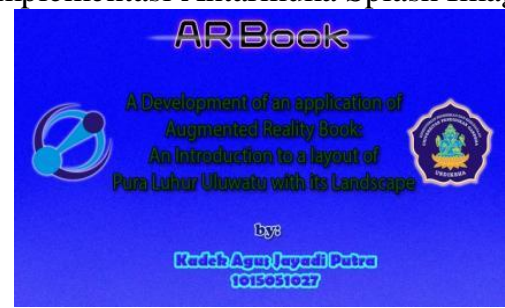

Gambar6.Implementasi Antarmuka Splash Image

c. Implementasi Layar Utama Aplikasi

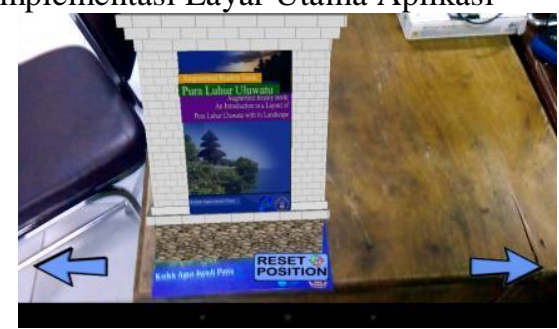

Gambar7a.Implementasi Tampilan Aplikasi Menampilkan Sampul Buku 
ISSN 2087-2658

Jurnal Nasional Pendidikan Teknik Informatika (JANAPATI)

Volume 4, Nomor 2, Juli 2015

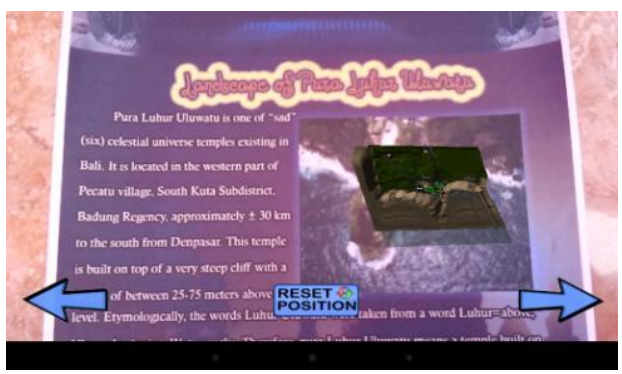

Gambar7b.Implementasi Tampilan Aplikasi Menampilkan Landscape Pura Luhur Uluwatu

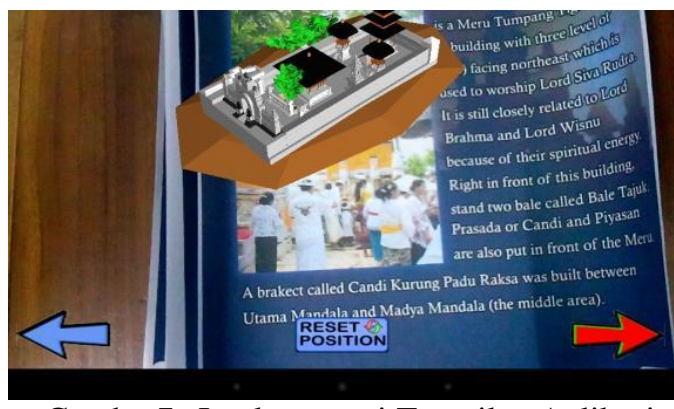

Gambar7c.Implementasi Tampilan Aplikasi Menampilkan Objek Utama Mandala Pura Luhur Uluwatu

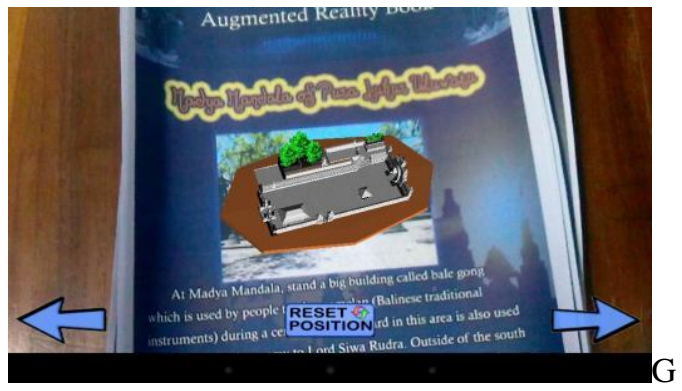

ambar7d.Implementasi Tampilan Aplikasi Menampilkan Objek Madya Mandala Pura Luhur Uluwatu

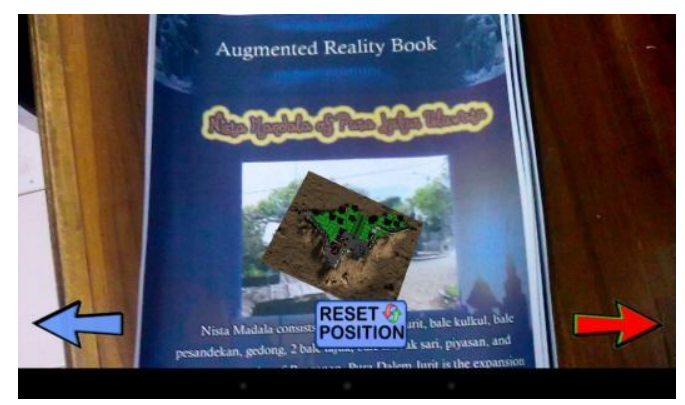

Gambar7e.Implementasi Tampilan Aplikasi Menampilkan Objek Nista Mandala Pura Luhur Uluwatu

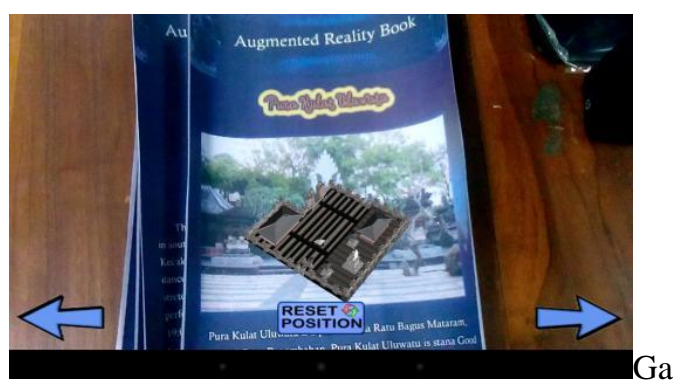

mbar7f.Implementasi Tampilan Aplikasi Menampilkan Objek Pura Kulat Uluwatu

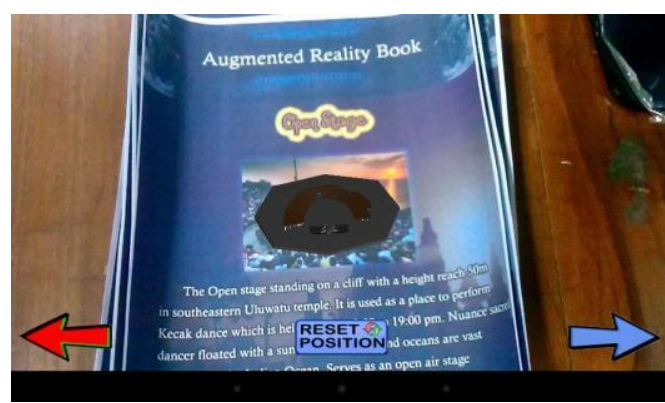

Gambar7g.Implementasi Tampilan Aplikasi Menampilkan Objek Open Stage

B.Pengujian Perangkat Lunak

Tahap selanjutnya setelah implementasi perangkat lunak adalah tahap pengujian perangkat lunak. Pada tahap pengujian ini akan dipaparkan mengenai tujuan pengujian perangkat lunak, pelaksanaan pengujian perangkat lunak serta evaluasi dari pengujian perangkat lunak.

1) Tujuan Pengujian Perangkat Lunak

Pengujian perangkat lunak aplikasi Augmented Reality Book Pengenalan Pengenalan Tata Letak Bangunan Pura Luhur Uluwatu beserta Landscape Alam dilakukan dengan mempergunakan pengujian black box testing. Dimana pengujian ini hanya dilihat berdasarkan keluaran yang dihasilkan dari data atau kondisi masukan yang diberikan untuk fungsi yang terdapat pada perangkat lunak tanpa melihat bagaimana proses untuk mendapatkan keluaran.

Adapun tujuan pengujian aplikasi Augmented Reality Book Pengenalan Tata Letak Bangunan Pura Luhur Uluwatu beserta Landscape Alam adalah:

1. Menguji kebenaran proses aplikasi Augmented Reality Book Pengenalan Tata Letak Bangunan Pura Luhur Uluwatu beserta Landscape Alam sesuai dengan 


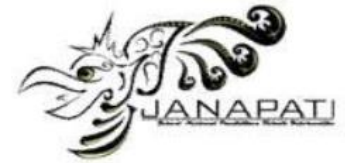

buku AR-Book Pura Luhur Uluwatu.

2. Menguji lama waktu menampilkan objek 3D pada aplikasi Augmented Reality Book Pengenalan Tata Letak Bangunan Pura Luhur Uluwatu beserta Landscape Alam yang menggunakan marker pada buku AR-Book Pura Luhur Uluwatu.

3. Menguji penggunaan aplikasi Augmented Reality Book Pengenalan Tata Letak Bangunan Pura Luhur Uluwatu beserta Landscape Alam pada tiga orang dengan menggunakan smartphone android yang berbeda.

2) Pelaksanaan Pengujian Perangkat Lunak

Berdasarkan perancangan pengujian perangkat lunak di atas, maka pengujian aplikasi Augmented Reality Book Pengenalan Tata Letak Bangunan Pura Luhur Uluwatu beserta Landscape Alam dilakukan oleh: 1) Pengembang untuk pengujian kesesuai proses aplikasi; 2) beberapa orang mahasiswa dari jurusan Pendidikan Teknik Informatika, Universitas Pendidikan Ganesha Singaraja. Pengujian dilakukan sesuai dengan kasus uji yang telah dirancang Sebelumnya dengan menggunakan tiga jenis angket yaitu:

1. Angket kesesuaian jalannya proses aplikasi dengan gambar pada buku

2. Angket lama waktu menampilkan objek 3D di luar ruangan dan di dalam ruangan

3. Angket penggunaan aplikasi pada jenis hardware berdeda

\section{C.Evaluasi Hasil Pengujian Perangkat Lunak}

Melalui hasil pengujian angket kesesuaian jalannya proses aplikasi dengan marker pada buku, maka diketahui bahwa proses aplikasi telah sesuai dengan AR-Book Pura Luhur Uluwatu. Semua proses aplikasi dapat berfungsi dengan baik. Suara dan objek 3 dimensi yang ditampilkan sesuai dengan marker pada buku, selain itu fitur softbutton untuk merotasi dan mereset objek mampu berfungsi dengan baik. Pada hasil pengujian melalui angket lama waktu untuk menampilkan (render) objek 3D pada siang dan malam hari, adalah dimana kedua kondisi memiliki waktu tercepat menampilkan (render) objek 3 dimensi yaitu pada saat jarak smart phone ke penanda (marker) adalah $30 \mathrm{~cm}$. Hal ini disebabkan karena ketika berjarak $10 \mathrm{~cm}$ dan $20 \mathrm{~cm}$, masih ada gambar penanda yang sulit terdeteksi oleh kamera secara keseluruhan, namun ketika
ISSN 2087-2658

Teknik Informatika (JANAPATI)

Volume 4, Nomor 2, Juli 2015 berjarak $30 \mathrm{~cm}$ keseluruhan dari gambar penanda dapat terdeteksi dengan baik oleh kamera, sehingga proses menampilkan (render) dapat lebih cepat dilakukan.

\section{V.SIMPULAN}

Berdasarkan hasil analisis, implementasi dan pengujian pada penelitian pengembangan aplikasi Augmented Reality Book Pengenalan Tata Letak Bangunan Pura Luhur Uluwatu beserta Landscape Alam, dapat ditarik kesimpulan sebagai berikut.

1. Aplikasi Augmented Reality Book Pengenalan Tata Letak Bangunan Pura Luhur Uluwatu beserta Landscape Alam dirancang menggunakan Flowchart Diagram dan Use Case Diagram dengan entitas pengguna (user).

2. Aplikasi Augmented Reality Book Pengenalan Tata Letak Bangunan Pura Luhur Uluwatu beserta Landscape Alam diimplementasikan dengan library Vuforia menggunakan aplikasi Unity 3D yang dapat melakukan pelacakan penanda sehingga mampu menampilkan objek 3 dimensi bangunan Pura Luhur Uluwatu beserta tata letaknya serta diikuti dengan suara narasi penjelasannya.

3. Berdasarkan hasil pengujian disimpulkan bahwa aplikasi Augmented Reality Book Pengenalan Tata Letak Bangunan Pura Luhur Uluwatu beserta Landscape Alam dapat berjalan lebih baik pada siang hari di luar ruangan dibandingkan pada malam hari di dalam ruangan. Berdasarkan kesesuaian proses aplikasi serta dapat digunakan pada beberapa hardware mengindikasikan bahwa aplikasi ini dapat dimanfaatkan sebagai sarana untuk memperkenalkan Pura Luhur Uluwatu kepada masyarakat local maupun asing, sehingga menarik minat mereka untuk mempelajari, memperkenalkan dan melestarikan Pura Luhur Uluwatu.

\section{REFERENSI}

[1]Ardana,IGustiGedeet.al.1990."PuraLuhurUluwatu", Denpasar:DinasKebudayaan ProvinsiBali

[2]Azuma,RonaldT.1997. "ASurveyofAugmentedReality".In Presence:TeleoperatorsandVirtualEnvironments6,4(August 1997).(hlm.355-385)

[3]BabadBali. 2000."TriHitaKaranadalamaAgamaHindu" http://www.babadbali.com/canangsari/trihitakarana.htmdiak sespada tanggal8Pebruari 2014

[4]Beautyathar.2011."CincinApidanFenomenanya".Kompasiana http://edukasi.kompasiana.com/2011/11/20/cincin-api-danfenomenanya-414316.htmldiaksespadatanggal 10Januari2014

$[5]$ Ruscita,Mas.2002."CatatanAkhirTahun2002,Tertenda
$n g$ Kuda 
ISSN 2087-2658

Jurnal Nasional Pendidikan Teknik Informatika (JANAPATI)

Volume 4, Nomor 2, Juli 2015

Balipost.http://www.balipost.co.id/balipostcetak/2002/12/31

/b16.htmdiakses padatanggal 10Januari2014

[6]Yulianingsih,TriMaya.2010."JelajahWisataNusantara".http://b ooks.google.co.uk/books?id=idM9qats3dsC\&pg=PR5\&lpg $=$ PR5\&source $=$ bl\&ots $=\mathrm{xHsj0}$ -

HIln\&sig=Ik0TYS85bVz0VIaZauv3402YxCc\&hl=en\&sa= $\mathrm{X} \& \mathrm{ei}=\mathrm{Ml}$

T2Uo6MNMqfkwXY1IGoBw\&ved=0CCkQ6AEwADgU\# $\mathrm{v}=$ onepag e \&q\&f=false (diakses pada tanggal 8 Februari 2014) 